科 学 通 报

\title{
人及猪脑源性神经营养因子基因克隆*
}

\author{
余云开 华仲慰 郭建荣 李玉书 汪家政 \\ (军事医学科学院基础医学研究所,北京 100850)
}

\section{关链词脑源性神经营茾因子、多聚酶链反应、基因克隆、DNA 序列测定}

脑源性神经营养因子(Brain-derived neurotrophic factor, BDNF) ${ }^{[1,2]}$ 主要是在中枢神经 系统内合成的小分子量碱性蛋白质, 由 119 个氨基酸组成. 研究发现 BDNF 对神经系统的多 种神经元均有效应, 在体与离体观察证明, 它可维持与促进外周神经嵴和基板来源的多种感觉 神经元的发育、生长与分化 ${ }^{[3-5]}$, 对中枢神经系统的基底前脑胆碱能神经元、GABA 能神经元、 中脑黑质多巴胺能神经元具有营养作用 ${ }^{[6,7]}$. 研究还发现 BDNF 与神经生长因子 (NGF) 同属 一个基因家族 ${ }^{[2,8,9]}$, 二者在生物效应上有许多类似之处, 但其作用的神经元特异性又有所不 同.

研究 BDNF 的生物学作用以及可能的临床应用, 需要获得一定数量的 BDNF. 然而 BD$\mathrm{NF}$ 在组织中的含量极微, 文献报道每千克组织仅可提取到微克水平 ${ }^{[1]}$. 这样低的含量, 加上 有效分析手段的缺乏, 极大地限制了 BDNF 研究的深入进行. 因此,迫切需要开展其基因工程 研究.

由于编码成熟 BDNF 的基因属于单一外显子结构, 不被内含子所分割 ${ }^{[2]}$, 因而可以采用 PCR 技术直接从基因组 DNA 中扩增目的基因, 避免了采用从 mRNA 提取到反转录获得基因 等一系列繁琐步骤. 考虑到在人和猪 BDNF 之间可能存在的核酸同源性, 我们用根据猪 BD$\mathrm{NF}$ 基因序列合成的引物, 试验以人基因组 DNA 为模板扩增人 BDNF 基因. 实验完成了人和 猪 BDNF 基因的克隆和序列测定.

\section{1 材 料 与 方 法}

\section{1 材料}

人胚胎脑组织来自五月龄胎儿, 分小块置液氮中冻存, 新鲜成年猪脑组织购自加工场, $-20^{\circ} \mathrm{C}$ 保存. 菌株 E. coli JM103 和载体 $\mathrm{M} 13 \mathrm{mpl} / 19$ 由本实验室提供. 限制性内切酶 BamH $\mathrm{I}$,Hind II , Sph I 为 BRL 产品, PCR 试剂盒为 Perkin-Elmer Cetus 产品,DNA 序列分析试剂 为 Pharmacia 产品, $\left[\alpha-{ }^{35} \mathrm{~S}\right] \mathrm{dATP}$ 购自 Amershen 公司.

\section{2 引物}

两引物的序列为:

\section{引物 I： $5^{\prime}$ CGGCATGCACTCGGACCCCGCCCGCC $\quad 3^{\prime}$,} Sph I 
引物 II : $5^{\prime}$ CCGGATCCTATCTTCCCCTCTTAATG $3^{\prime}$.

BamH I

\section{3 基因组大分子量 DNA 的提取和纯化}

脑组织在液氮中冻硬后,于研针中边加液氮边捣碎成粉末,加到 10 倍体积的提取缓冲液 中 ( $10 \mathrm{mmol} / \mathrm{L}$ Tris-HCl, pH8. 0, 0. $1 \mathrm{~mol} / \mathrm{L}$ EDTA, $20 \mu \mathrm{g} / \mathrm{ml}$ RNAase (无 DNAase), $0.5 \%$ $\mathrm{SDS}$, 摚拌均匀. $37^{\circ} \mathrm{C}$ 捊育 $1 \mathrm{~h}$ 后, 加入蛋白酶 $\mathrm{K}(100 \mu \mathrm{g} / \mathrm{ml})$, 温和混匀, $50^{\circ} \mathrm{C}$ 水浴 $3 \mathrm{~h}$, 冷至室 温. 等体积平衡酚 ( $\mathrm{pH} 8.0$ ) 抽提 3 次. 上层水相加入 $1 / 5$ 体积 $10 \mathrm{~mol} / \mathrm{L}$ 醋酸铵和 2 倍体积乙 醇 (室温), $6000 \mathrm{r} / \mathrm{min}$ 离心 $5 \mathrm{~min}$ 收集沉淀, $70 \%$ 乙醇洗 2 次. 沉淀稍干溶于 $\mathrm{TE}(\mathrm{pH} 8.0)$.

\section{4 PCR 扩增}

直接以提取的基因组大分子量 DNA 为模板. 反应体系: 模板 DNA $1 \mu \mathrm{g}$, 两引物各 $1 \mu \mathrm{mol} / \mathrm{L}, 4$ 种 $\mathrm{dNTP}$ 各 $200 \mu \mathrm{mol} / \mathrm{L}, \mathrm{Taq}$ DNA 聚合酶 $2.5 \mathrm{U}$,总体积 $100 \mu \mathrm{l}$. 变性 $94^{\circ} \mathrm{C} \times 1^{\prime}$,引 物退火 $55^{\circ} \mathrm{C} \times 1^{\prime}$, 链延伸 $72^{\circ} \mathrm{C} \times 2^{\prime}$, 扩增 30 个周期. 反应后取 $5 \mu \mathrm{l}$ 样品进行 $2 \%$ 琼脂糖凝胶电 泳检查扩增结果.

\section{$1.5 \mathrm{M13}$ 克隆与 DNA 序列测定}

电泳纯化的 PCR 产物与 $\mathrm{M} 13 \mathrm{ml} / 19$ 的连接、感受态细胞制备、RF DNA 转化及重组子笠 选按分子克隆方法进行. 参照 Phamacia 推荐方法制备单链重组 DNA, 用双脱氧末端终止法 进行 DNA 序列测定.

\section{2 实 验 结 果}

按照已发表的猪 BDNF 基因序列设计合成引物, 分别以人和猪基因组大分子量 DNA 为 模板 PCR 扩增 BDNF 基因. PCR 反应后的 2 种产物,均在 $2 \%$ 琼脂糖凝胶电泳中显示出符合 预期 374bp 大小的 DNA 片段(图 1).

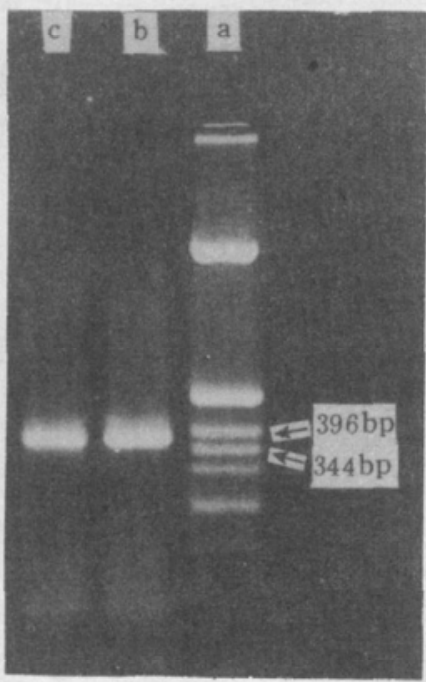

图 1 PCR 产物 $2 \%$ 琼脂糖凝 胶电泳结果

$\mathrm{a}-\mathrm{pBR} 322 / \mathrm{HinF} \mathrm{I}$, 作为分子量标准;

$\mathrm{b}$ - 人基因组 DNA PCR 产物;

c一一猪基因组 DNA PCR 产物

PCR 产物经 Sph I 、BamH I 双酶切电泳回收后,与同 样双酶切的 M13mp18/19 RF DNA 连接, 转化 $E$. coli JM103 受体菌, 挑取白色噬菌斑, 快速抽提重组 DNA 进行 酶切鉴定. 结果初步证实克隆的两目的 DNA 为 BDNF 基因 (数据未列出). DNA 序列测定结果 (图 2) 进一步证实人 BDNF 基因与文献报道的猪 BDNF 基因大小一样,均为 $357 \mathrm{bp}$, 即人 BDNF 蛋白质同样由 119 个氨基酸组成. 猪 BDNF 基因序列与文献报道的序列相比,有一个碱基不同, 在第 288 位置上的 $A$ 被 $G$ 取代,但由于此核苷酸位于赖氨 酸密码子的第三位上,故并未改变蛋白质本身的氨基酸顺 序. 人 BDNF 基因序列与本实验得出的猪 BDNF 序列相比, 有 29 个碱基不同,绝大部分的碱基改变发生在氨基酸密码 子的第三位上,仅第 289 位例外, 碱基 C 被 A 取代,它位于 氨基酸密码子的第一位, 由 CGA 改变为 AGA. 但由于此二 密码子均编码精氨酸, 故仍不改变其顺序. 从克隆的人和猪 BDNF 基因序列推导,二者氨基酸顺序完全一致.

\section{3 讨 论}

所克隆的猪 BDNF 基因序列与 Leibrock 等人报道的序 
His Ser Asp Pro Ala Arg Arg Gly Glu Leu Ser Val Cys Asp Ser lle Ser Glu Trp Val pBDNF CAC TCG GAC CCC GCC CGC CGC GGG GAG CTG AGC GTG TGC GAC AGC ATT AGC GAG TGG GTG

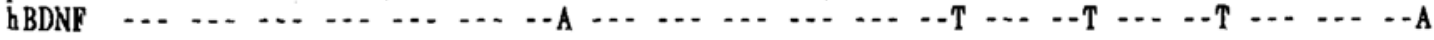
Thr Ala Ala Asp Lys Lys Thr Ala Val Asp Met Ser Gly Gly Thr Val Thr Val Leu Gilu pBDNF ACG GCG GCG GAT AAA AAG ACG GCA GTG GAC ATG TCG GGT GGC ACG GTC ACG GTC CTC GAA

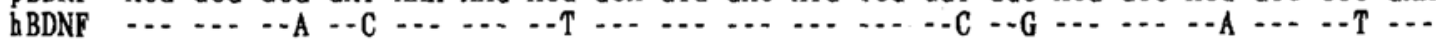
Lys Val Pro Val Ser Lys Gly GIn Leu Lys Gln Tyr Phe Tyr Glu Thr Lys Cys Asn Pro pBDNF AAA GTC CCC GTC TCG AAA GGC CAA CTG AAG CAG TAC TTC TAC GAG ACC AAG TGC AAT CCT

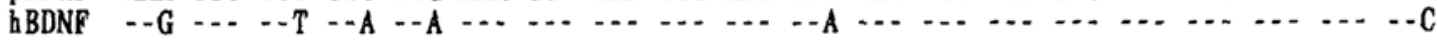
70 80 Met Gly Tyr Thr Lys Glu Gly Cys Arg Gly Ile Asp Lys Arg His Trp Asn Ser Gln Cys PBDNF ATG GGG TAC ACA AAG GAG GGC TGC AGG GGC ATA GAC AAG AGG CAC TGG AAC TCC CAG TGC

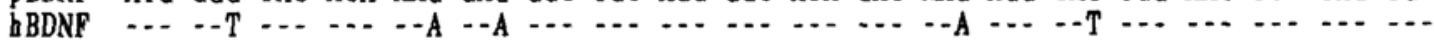
Arg Thr Thr Gln Ser Tyr Val Arg Ala Leu Thr Met Asp Ser Lys Lys Arg Ile Gly Trp pBDNF CGA ACT ACC CAG TCG TAT GTG CGG,GCC CTC ACC ATG GAT AGC AAA AAG CGA ATT GGC TGG

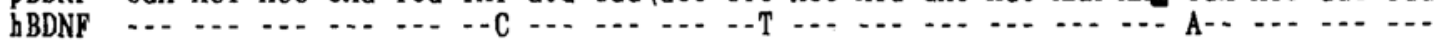
110

Arg Phe Ile Arg Ile Asp Thr Ser Cys Val Cys Thr Leu Thr Ile Lys Arg Gly Arg

PBDNF CGG TTC ATA AGG ATA GAC ACT TCC TGT GTA TGT ACT TTG ACC ATT AAG AGG GGA AGA

hBDNF

图 2 测定的人和猪 BDNF 基因序列

血西为引物 1 、引物 1 匹配区; س 为第 288 位碱基

列相比,有一个碱基不同,第 288 位置上的 $\mathrm{A}$ 改变为 $\mathrm{G}$,我们认为此碱基的差异可能是由于所 用模板 DNA 来源于不同的猪种所致,但也存在 PCR 反应过程中发生碱基错配的可能性. 我 们实验中克隆的人和猪 BDNF 基因序列与 Jones ${ }^{[10]}$ 所测定的人 BDNF 基因序列在此位置上 的碱基均为鸟嘌呤 $(G)$,因此有理由认为猪 BDNF 基因的第 288 位置的碱基更可能为鸟嘌呤 G. 最终结果判定尚需进一步的实验证实.

本实验所克隆的人 BDNF 基因序列与 Jones 报道的人 BDNF 基因序列相比,所用引物匹 配区之间的序列完全相同,而引物匹配区内的序列存在差别,有 3 个碱基不同,这是因为我们 实验所用的引物是根据猪 BDNF 基因序列合成的. 当时尚未见人 BDNF 基因序列的报道. 采 用合成的猪 BDNF 基因两端引物通过 PCR 扩增出了人 BDNF 基因证实了我们当初的设想, 即人和猪 BDNF 可能有相当大的同源性,因此存在着用一种引物匹配 2 种模板的可能性. 同 时也说明引物与模板之间的少数碱基不匹配或者引物 $3^{\prime}$ 端完全匹配的碱基数较少,PCR 反应 同样能扩增出特异目的 DNA.

\section{参考 文 献}

[1] Barde, Y. A., Edgar, D. , Thoenen, H. , EMBO J. , 1982, 1:549-553.

[2] Leibrock, J., Lottspeich, F., Hohn, A. et al. , Nature, 1989, 341:149-152.

[ 3 ] Lindsay, R. M. , Thoenen, H. , Barde, Y. A. , Dev. Biol. , 1985, 112(2):319-328.

[ 4 ] Kalcheim, C. , Barde, Y. A. , Thoenen, H. et al. , EMBO J., 1987, 6:2871-2873.

[5] Hofer, M. M. , Barde, Y. A. , Nature, 1988, 331:261-262.

[6] Knusel, B., Winslow, J., Rosenthal, A. et al., Proc. Natl. Acad. Sci. USA, 1991, 88:961-965.

[ 7] Hyman, C. , Hofer, M. , Barde, Y. A. et al. , Nature, 1991, 350:230-232.

[ 8] Hohn, A., Leibrock, J., Bailey, K. et al., Nature, 1990, 344:339-341.

[9] Maisonpierre, P. C. , Belluscio, L., Squinto, S. et al. , Science, 1990, 247 :1446-1451.

[10] Jones, K. R., Reichardt, L. F., Proc. Natl. Acad. Sci. USA, 1990, 87:8060-8064. 